\title{
Karate today: are there any national differences in the approach?
}

\author{
Petr Skryja, Martin Zvonař, Marta Gimunová
}

Faculty of sport studies, Masaryk university

\begin{abstract}
The study is based on the research of the current research for participation in karate, especially in Europe and the United States. The analysis of literature and then the follows commentary summarizes the central themes and explains them in the context of specific situations and developments of karate schools in individual countries.
\end{abstract}

\section{INTRODUCTION}

Generally, three approaches toward karate can be distinguished: a pedagogical or humanistic approach focused on improving the personality of the practitioner; treating karate as entertainment; and worshiping the power and focusing on the highest efficiency in fighting (Cynarski, 2014). In Europe, the dominant approach as the result of its commercialization is treating karate as entertainment (Cynarski, 2014) or a sport (Szabo et al., 2017). The primary emphasis is therefore on the physical aspect of training and on winning instead of body awareness and spirituality (Szabo et al., 2017). However, the results of previous studies focused on the main motives for practicing karate in different countries often vary. On the other hand, for example, hard martial arts may be beneficial for improving some selected aspects of cognitive function across the lifespan. Because only a few studies used randomized controlled trials, a definitive conclusion regarding the beneficial effects of martial arts on cognitive functions is still difficult to be made at this stage. To better understand the effects of martial arts for cognitive function across the lifespan, future research should involve larger sample sizes, well-controlled designs, standardized assessments and long-term follow-ups, measures of health status, exercise intensity, leisure time activities, and session attendance rates (Ly, 2018).

Therefore, this study aims to make a comprehensive review of the primary motives for practicing karate found in previous studies in different countries and compared the findings with the situation in the Czech Republic.

\section{METHODS}

The study is based on research into the field of motifs for karate training and long-term participating.

The main method is the analysis of professional literature concentrated on focusing on mapping the critical themes for participation in karate teaching and learning and then a commentary summarizing the findings of individual studies.

During the study, we analyzed a total of 5 research studies related to the topic of work, whose primary research tool is questioning. 


\section{RESULTS}

\section{Poland}

In Poland, the primary motive for practicing the martial art was found to be obtaining the real self- defense skills. The second most prevalent motive was found to be following the great masters by the path of karate throughout their lives. In the countries where the karate achieved the highest level of development, a great interest in the history and tradition was observed. Excellent knowledge of martial arts and history was declared by $25 \%$ of the Poland karate practitioners. $50 \%$ of the karate practitioner found the spiritual development to be the highest value of their practice (Kusnierz 2011).

A study by Kusnierz (2011) a questionnaire was applied to 50 karate practitioners (40 men, 10 women), aged 19-24, Shotokan karate style.

\section{Portugal}

The development of karate in Portugal to a certain extent is also related to the historical development of the country, a colonialist past which has made it possible to intensify the interconnection of very distant cultures, which is particularly evident in Portugal. Both historical and contemporary schools are at first sight very close to Eastern philosophies, originating from the original Japanese karate. In Portugal, the principles of budo which give a deeper meaning to karate practice were reported to be the main outcome for the karate practitioners. As for the most important reasons to practice karate, physical and psychological well-being, development and behavior in nature (e.g., self-control, respect, discipline), the pleasure of the practice of karate and mental development (concentration, mental ability) were in the top five (Rosa, 2012).

In the study by Rosa (2012) a questionnaire was applied to 169 karate practitioners (146 males, 23 female), 90 of them Shotokai style, 32 Shotokan style, 25 Goju-Ryu style and 22 Wado-Ryu style.

\section{England}

In England, the most crucial factor for participation in martial arts were affiliation (like the instructor, challenge, enjoy individual aspect), fitness (stay in good physical shape, exercise), skill development (improve martial art skills, get to higher level) and friendship (be with friends, have something to do, meet new friends). The philosophy and mind and body concept of martial arts importance was not evident from the results of the applied questionnaire (Jones et al., 2006).

74 (56 males, 18 females) martial art practitioners (including karate) participated in this study (Jones et al., 2006).

For English schools, karate is the paramount influence of multiculturalism, which has historically led to the stratification of the population represented by the standard as a concern with a club, while not limiting its individualism.

\section{United States}

A high-level of motivation for karate practitioners in the United States was found to be self-defense and aggression. Additionally, fun, physical fitness and to a lesser extent a cultural awareness were factors of motivation found to affect the participation in martial arts (Ko, Kim, 2010). In this study, 325 martial art (including karate) practitioners (225 males, 81 female) participated by completing a questionnaire (Ko, Kim, 2010).

However, just as in the Czech Republic, both the basic concepts of karate, that is to say, the direction that respects the traditional karate pronouns and the direction that prefers the competition or the racing concept, are widespread in the United States of America. Both concepts are 
represented by a number of schools, organizing various competitions, competitions and championships. For American karate, it is typical of intensive cooperation with schools in Japan and also in Europe.

\section{Czech Republic}

When assessing the situation in the Czech Republic, I draw on my own long-standing experience, which allows me to take a broad look at the situation.

In the Czech Republic, there are two main streams in the steam like in the United States. One direction is characterized by a focus on personality development in all aspects, is mental and physical development.

The second direction can be characterized as sport karate, so it is a typical organization of competitions, like in any sport (basketball, football, etc.) and the main emphasis is put on the competition.

Looking at the motives for karate exercises in childhood, the Czech Republic has a strong influence on parents, their main motive being to teach children how to assess the severity of the situations that may lead to conflict, how to prevent these conflicts and how to solve them. In other words, it is about self-defense. For adults, the main reason for engaging in karate training is two reasons, both the development of the mental and physical aspects of the personality along with the growing motives for improving the skill of self-defense.

\section{CONCLUSION}

Findings of the current study confirm differences in the approach toward karate practice in different countries. The role of the instructor was highlighted as a major aspect of motivation for participation in karate training in a study carried out in England. Fun and physical fitness were important factors of motivation found in studies from the United States, England, and Portugal. Obtaining self-defense skills as the main motive for practicing the martial art was reported in a study from Poland and United States. However, in all analyzed countries the principles of budo were to a greater or lesser extent also reported as a key factor for practicing karate. One of the key factors for karate practice is the inclusion of combative sports education in general in curricula of primary and secondary education. Here, within Europe, there is a great diversity, not only in the volume, but also in the amount of education directed at the struggles, but especially in the objectives of the education of the allies. While in the United States, the promotion of self-defense is the main reason for incorporating tutoring into curricula, not just in the post-communist countries of Europe the reasons are gradually changing. Gradually, the center of gravity moves from the promotion of general fitness to the development of self-defense. However, this trend is significantly related to the security situation of each country, and very gemma- nalizingly it can be said that the greatest emphasis on self-defense is logically put in countries with a worse security situation.

\section{References}

- Cynarski, W. J. (2014). The European karate today: The opinion of experts. Ido Movement for Culture. Journal of Martial Arts Anthropology", vol. 14, no. 3, pp. 10-21

- Szabo, A., Soós, I., Veghseo, V., Ruíz-Barquín, R., Boros, S. (2017). Cross-sectional examination of a presumed connection between long-term Shotokan karate training, body awareness, and spirituality. Asia Pacific Journal of Sport and Social Science, 6,2, 118-125.

- Kuśnierz C. (2011), Values associated with practicing modern karate as a form of cultivating old Japanese Bushido patterns, "Ido Movement for Culture. Journal of Martial Arts Anthropology", vol. 11, no. 4, pp. 1-5. 
- Rosa V. A. V. (2012), "Samurais" in modern Europe: motivations and understanding of Portuguese karatekas, "Ido Movement for Culture. Journal of Martial Arts Anthropology", vol. 12, no. 2, pp. 11-19.

- Jones, G. W., Mackay, K. S., \& Peters, D. M. (2006). Participation Motivation In Martial Artists In The West Midlands Region Of England. Journal of Sports Science \& Medicine, 5(CSSI), 28-34.

- Ko, Y. J., Kim, Y. K. (2010). Martial arts participation: consumer motivation. International Journal of Sports Marketing and Sponsorship, 11, 2, 2-20. 